\title{
Jet Quenching Simulation with Consideration for Distribution of Heat Transfer Coefficient and Latent Heat for Martensitic Transformation under Rapid Cooling
}

\author{
Hirohisa TAKEUCHI* and Yasuhiro YOGO \\ Toyota Central R\&D Lab., Inc., 41-1, Yokomichi, Nagakute, Aichi, 480-1192 Japan. \\ (Received on May 26, 2020; accepted on September 30, 2020)
}

\begin{abstract}
The accurate simulation of jet quenching is required to optimize the dimensions of the cooling jacket, the positional relationship between the cooling jacket and workpiece, and the various cooling parameters (such as the flow rate of the jet and the cooling time) without requiring a trial-and-error empirical approach. In this study, for the purpose of developing an accurate and simple jet quenching simulation technique without using the CFD simulation, heat transfer between surface of a workpiece and jet is summarized using heat transfer coefficients which depend on surface temperature of a workpiece and jet density. Additionally, because a martensitic transformation occurs during the quenching of carbon steels, the latent heat of this transformation was incorporated into the simulation. A means of obtaining the latent heat for martensitic transformation during rapid cooling was also developed and used in the simulation. Providing heat transfer coefficients adequate for practical use improved the prediction accuracy for the overall quenching process, and consideration of the latent heat for martensitic transformations under rapid cooling increased the accuracy, in particular below $473 \mathrm{~K}$, which is the onset temperature for the martensitic transformation. When experimental temperature of workpiece was $339 \mathrm{~K}$, after 1 seconds of cooling time, the error between the experimental and calculation results for tooth bottom of a gear was approximately $4 \mathrm{~K}$. This error is 14 times smaller than that obtained with a conventional calculation without consideration of the heat transfer coefficients which depend on surface temperature and jet density and latent heat of martensitic transformation.
\end{abstract}

KEY WORDS: jet quenching; heat treatment; simulation; latent heat; martensitic transformation.

\section{Introduction}

Computer simulations of heat treatment processes have been widely studied and are used to optimize parameters such as the temperature distribution, ${ }^{1)}$ microstructure, ${ }^{2)}$ distortion and residual stress. ${ }^{3)}$ In these simulations, an accurate prediction of the variations in the temperature of a workpiece during heating and quenching is required so as to simulate the heat treatment phenomena accurately. As an example, Takeuchi et al. ${ }^{4)}$ developed an accurate method for simulating the induction heating technique that is widely used for the heat treatment of steel parts.

Quenching treatments can be categorized as either immersion processes (in which a workpiece is cooled by soaking in a quenchant) or jet processes (in which a workpiece is cooled by a quenchant that is jetted from a cooling jacket). ${ }^{5)}$ Computational fluid dynamics (CFD) simulations have been carried out to model immersion quenching, and there has been good agreement between experimental data and

\footnotetext{
* Corresponding author: E-mail: take-hrhs@mosk.tytlabs.co.jp
}

calculated temperatures. ${ }^{6)}$ However, CFD cannot readily be applied to jet quenching, which comprises a number of complex phenomena, including impingement between the jet and workpiece, boiling, dispersion and re-contact. ${ }^{7)}$ Because of this complexity, the calculation costs associated with CFD simulations of jet quenching are exceedingly high and it is difficult to use CFD to optimize quenching conditions.

The purpose of this study was to develop an accurate and simple jet quenching simulation technique without using CFD. Accurate material characteristics and boundary conditions, such as heat transfer coefficients, are required to properly simulate the physical phenomena in such processes. During jet quenching, the boiling of the quenchant can be ignored because the quenchant pressure is sufficient to break the boiling layer at the workpiece surface, such that fresh quenchant is always supplied to the surface. This process is therefore quite different from immersion quenching. Consequently, the heat transfer coefficients for each cooled surface during jet quenching must be expressed as functions of surface temperature and jet density (that is, the jet flow rate per unit area of cooled surface). Therefore, heat transfer 
coefficients were focused on and identified in this study.

The quenching of steel parts generally experiences induce a martensitic transformation. During this process, the specific heat and heat conductivity of the workpiece change and an exothermic reaction occurs due to the latent heat of the transformation. Thus, the martensitic transformation greatly affects the temperature of the workpiece and has to be considered in quenching simulations. The latent heat of a quasi-static phase transformation such as an austenite to ferrite-perlite transition can be determined by differential scanning calorimetry ${ }^{8)}$ and differential thermal analysis. ${ }^{9)}$ However, these methods typically employ cooling rates of less than several K/s, which are much lower than the cooling rates that accompany the martensitic transformation of steel (approximately $100 \mathrm{~K} / \mathrm{s}$ ). As an example, Kuang et $a l$. measured the latent heat associated with the martensitic transformation of Co while applying a maximum cooling rate of just $16 \mathrm{~K} / \mathrm{min}^{.1{ }^{10)}}$ For these reasons, the present study also devised a simple method of identifying the latent heat of martensitic transformation in response to rapid cooling.

This paper is organized as follows. In Section 2, a technique for finding the heat transfer coefficients is described and some basic experiments intended to validate this method are reported. The heat transfer coefficients obtained for various jet densities and surface temperatures are discussed in Section 3, while the latent heat values for rapid cooling are provided and incorporated into the simulation in Section 4. The simulation of the quenching of a gear is demonstrated in Section 5 and conclusions are presented in Section 6.

\section{Determination of Heat Transfer Coefficients}

\subsection{Experimental and Calculation Methods}

Fukuda reported that quenchant density is one of the primary factors affecting cooling behavior during the steelmaking process. ${ }^{5)}$ Based on this concept, the heat transfer coefficients between the jet and the workpiece surface were investigated in this study. These coefficients would be varied by four factors; i) the surface temperature of the workpiece, ii) the flow rate of the jet (Fig. 1(a)), iii) the area of the cooled surface (Fig. 1(b)), and iv) the shape of the cooled surface (Fig. 1(c)). In order to simplify the simulations, factors ii) and iii) were both incorporated into a jet density term, defined as the flow rate of the jet per unit area of surface, in $\mathrm{mL} / \mathrm{mm}^{2} \cdot \mathrm{min}$. Figure 2 illustrates the calculation of jet density based on the application of a jet to two surfaces: A and B. Surface A faces and is parallel to the cooling jacket surface while surface B is slanted at an angle of $45^{\circ}$. The same jet quantity is sprayed onto surfaces $A$ and $B$ but the area of surface $B$ is $\sqrt{2}$ times larger than that of surface A. Thus, the jet density at surface $A$ is $\sqrt{2}$ times larger than that at surface B. Based on this scenario, even if quenching conditions such as flow rate are changed, the quenching behavior should be the same because the jet density is the same. A number of preliminary quenching experiments that allowed the determination of heat transfer coefficients were carried out to confirm this point.

Figure 3 presents a schematic diagram of the experimental quenching process, while details of the workpiece, the heating coil, and the cooling jacket are shown in Fig. 4. Initially, the workpiece was heated to $1093 \mathrm{~K}$ and main-
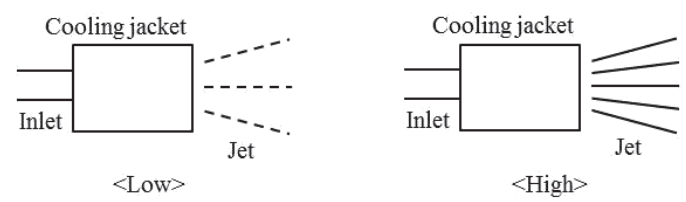

a. Flow rate
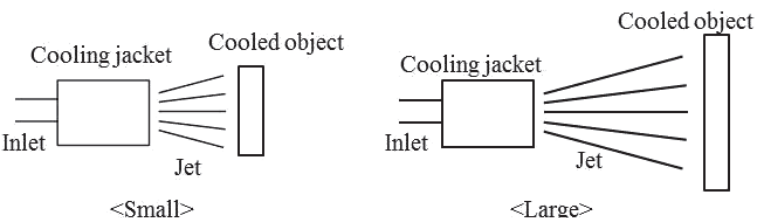

b. Area of cooled surface
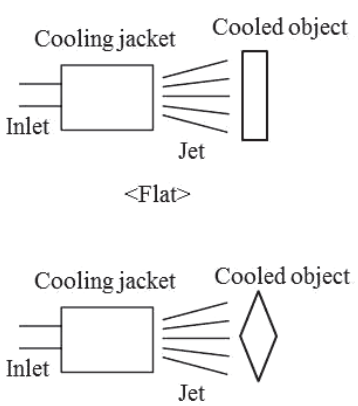

$<$ convex $>$

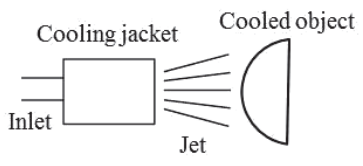

$<$ circular arc $>$

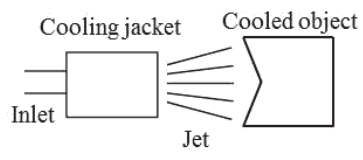

$<$ concave $>$ c. Shape of cooled surface

Fig. 1. Schematic diagrams of the factors affecting the heat transfer coefficient.

tained at that temperature for $40 \mathrm{~s}$ by induction heating. The workpiece was subsequently moved next to the cooling jacket and quenched by the jet, which was sprayed from orifices in the jacket. Note that a columnar workpiece and a flat cooling jacket were used in these trials and that the orifice diameter was $1 \mathrm{~mm}$ while the surface area of the cooling jacket was $0.0032 \mathrm{~m}^{2}$. The default number of cooling jacket holes was 39 but this value was varied between 33 and 24 using closure screws, as shown in Fig. 5. In this study, 5\% POE alkyl ether solution was used as coolant. Temperature of coolant was approximately $298 \mathrm{~K}$. The coolant flow rate, which was measured by a flowmeter, was held constant at $53 \mathrm{~L} / \mathrm{min}$ in these experiments such that the jet density also remained constant. The surface temperature of the workpiece was monitored using a type $\mathrm{K}$ thermocouple welded to its surface. The workpiece was made of austenitic stainless steel (JIS SUS304) so as to produce quenching curves without an austenite to martensite phase transformation.

To clarify the effect of factor iv), the heat transfer coefficients of two different workpieces (A and B) were determined. These two workpieces and the flat cooling jacket are shown in Fig. 6. The cooled surfaces of both workpieces faced the cooling jacket surface slanted at an angle of $22.5^{\circ}$, such that the cooled surface area and jet density were the same for both. However, the cooled surface of workpiece A was convex while that of B was concave, and so the flow behavior of the jet after contacting the surface was different between the two workpieces. Specifically, the jet flowed to both sides of workpiece A but was concentrated at the base of the concave shape of workpiece B. The workpieces were heated to $1173 \mathrm{~K}$ and maintained at that temperature for $40 \mathrm{~s}$, 


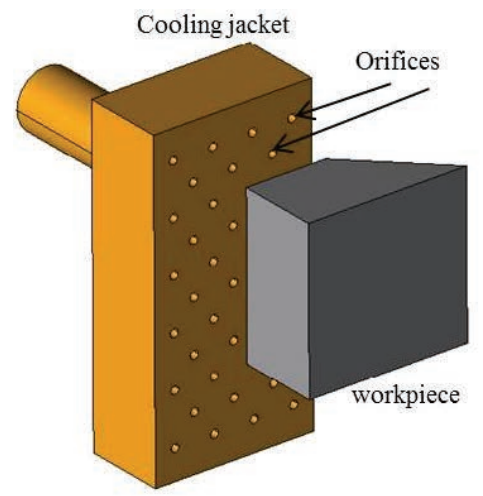

a. Schematic diagram

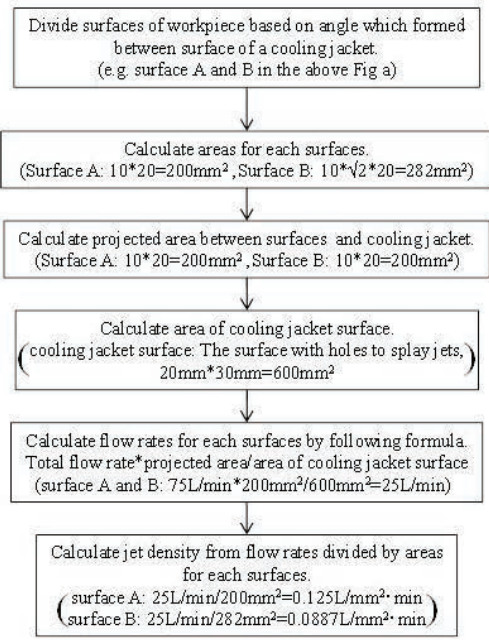

d. Flow to calculate jet density

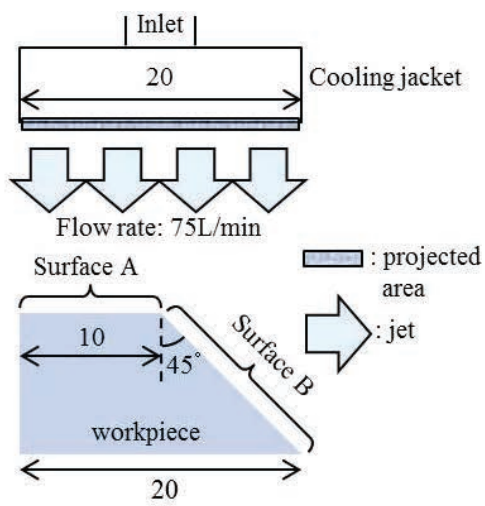

b. top view

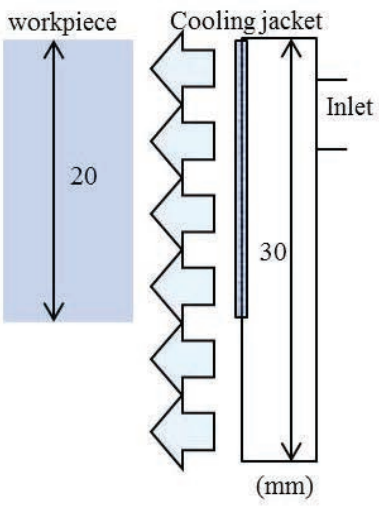

c. side view

Fig. 2. Diagrams showing the method used to calculate the jet density. (Online version in color.)

then quenched by the jet. In these trials, the workpieces were also made of austenitic stainless steel (JIS SUS304) and the surface temperatures of both workpieces were also measured.

Computational modeling that simulated these quenching experiments was conducted to find the heat transfer coefficients for the convex and concave surfaces. The simulation models developed for both workpieces had the same dimensions, and heat transfer as a boundary condition between the jet and each workpiece was defined at the cooled surfaces. A constant heat transfer coefficient ranging from 1250 to $45000 \mathrm{~W} / \mathrm{m}^{2} \cdot \mathrm{K}$ was defined for each model. The initial temperature of the workpiece was $1173 \mathrm{~K}$ and this temperature was uniform throughout the object. The temperaturedependent thermal conductivity and specific heat values for SUS304 (Fig. 7) were used in these calculations. The mesh size was $1 \mathrm{~mm}$ and the time step during calculations was set at $0.01 \mathrm{~s}$. Calculations were conducted using the commercial finite element method (FEM) software package JMAG (JSOL Co., Ltd.).

A schematic diagram showing the determination of the temperature-dependent heat transfer coefficient from experimental and simulated quenching curves is provided in Fig. 8. Here, the dashed line represents the experimental quenching data while the solid lines are calculated quenching curves for each heat transfer coefficient. It is evident that the experimental and simulated plots for heat transfer coefficient $=20000$ $\mathrm{W} / \mathrm{m}^{2} \cdot \mathrm{K}$ intersect at $720 \mathrm{~K}$, indicating that this is the value of the heat transfer coefficient at this surface temperature. In the same manner, it was determined that the coefficients were 10000 and $5000 \mathrm{~W} / \mathrm{m}^{2} \cdot \mathrm{K}$ at 480 and $340 \mathrm{~K}$, respectively.

\subsection{Experimental and Simulated Results}

The quenching curves generated using different numbers of holes in the cooling jacket with a constant jet flow rate are shown in Fig. 9. It is apparent that the quenching behavior was almost the same in each case. Figures 10(a) and 10 (b) present a comparison of the quenching curves and temperature-dependent heat transfer coefficients between the convex and concave workpieces, which demonstrates that the convex workpiece was quenched more rapidly as a result of its smaller volume. It is also evident that the temperaturedependent heat transfer coefficients for both workpieces were almost equal. These results indicate that quenching conditions can be summarized with jet density, and shape of the cooled surface is negligible. Therefore, it is possible to conduct jet quenching simulations by incorporating the jet density and the temperature of the workpiece when assessing the heat transfer coefficient.

\section{Determination of Heat Transfer Coefficients at Vari- ous Jet Densities}

\subsection{Experimental and Calculation Methods}

A columnar workpiece and a ring-shaped cooling jacket were used to determine the heat transfer coefficients at various jet densities. A schematic diagram of the experimental 


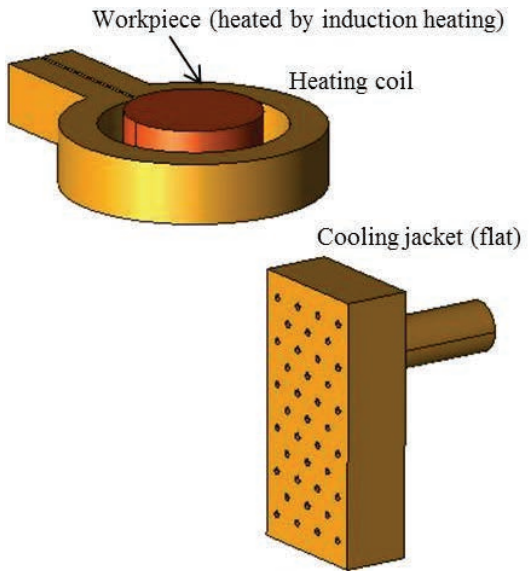

a. Heating

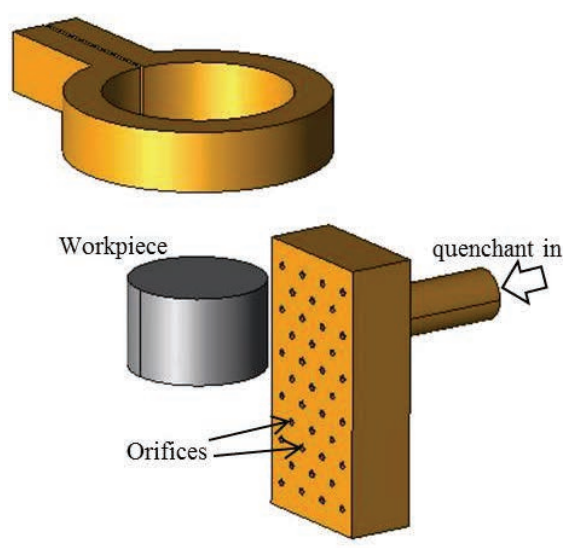

b. Quenching

Fig. 3. Schematic diagram of the apparatus used during the quenching experiments with a flat cooling jacket. (Online version in color.)

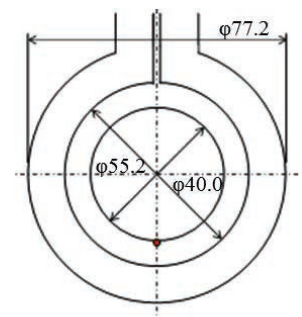

Top view

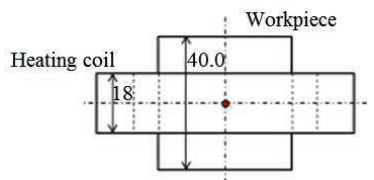

Side view

a. Heating

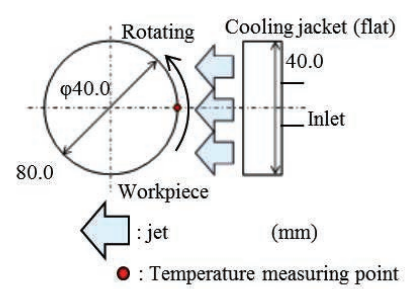

Top view

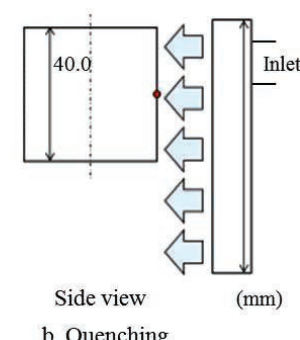

b. Quenching
Fig. 4. The dimensions of the workpiece, heating coil and cooling jacket used in the quenching experiments. (Online version in color.)

apparatus is shown in Fig. 11, while details regarding the dimensions of the workpiece, the heating coil, and the cooling jacket are provided in Fig. 12. In these trials, the workpiece was heated to $1303 \mathrm{~K}$ and maintained at that temperature for $40 \mathrm{~s}$, then quenched by a jet. The material used was
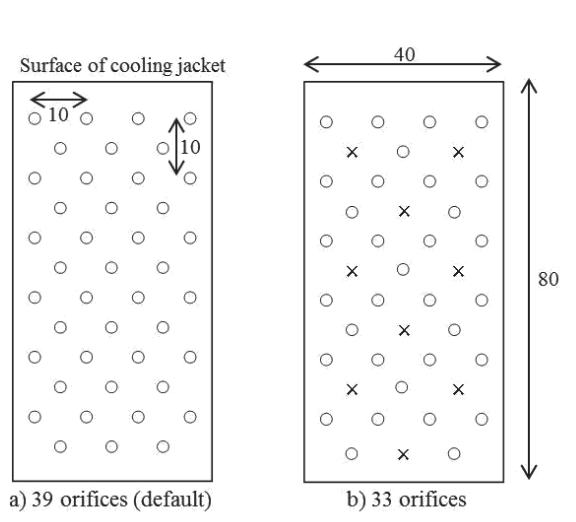

O: Orifices(opening)

$\times$ : Orifices (closed by a screw)

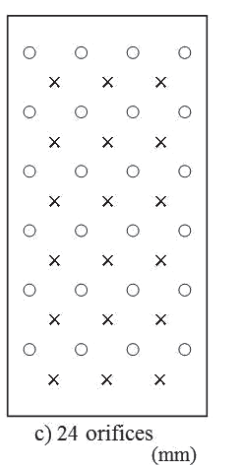

Fig. 5. The layout of the orifices.
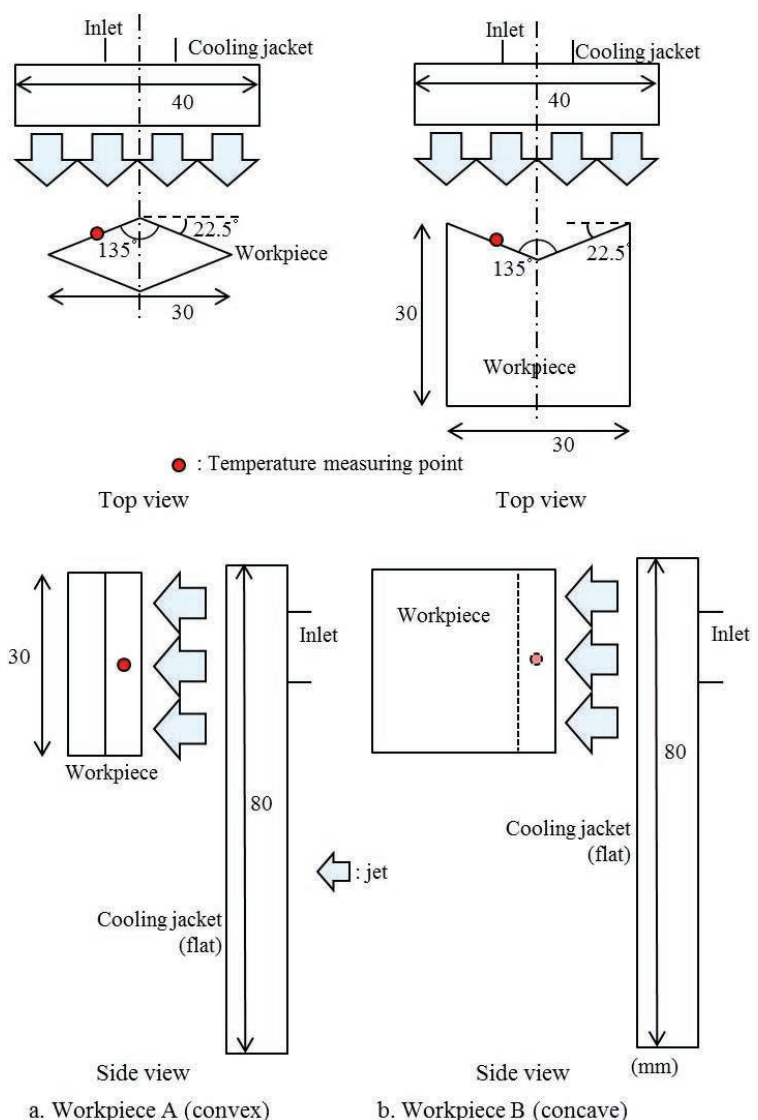

Fig. 6. The dimensions of the workpiece and cooling jacket used in the quenching experiments. (Online version in color.)

again austenitic stainless steel (JIS SUS304) and the surface temperature of the workpiece was again monitored. Calculations were conducted to find the heat transfer coefficients.

\subsection{Results of Coefficient Determinations}

Figure 13 shows the relationship between the jet density, the workpiece surface temperature and the heat transfer coefficient. These data indicate that the heat transfer coefficient was increased with increases in the jet density and decreases in the surface temperature. Nakata et al. ${ }^{11)}$ determined the heat transfer coefficients of plate steel specimens at various surface temperatures with a constant jet flow rate and also reported that the coefficient increased at lower surface temperatures or higher flow rates. Heat transfer 
coefficient is affected by temperature, flow rate, and chemical composition of coolant and surface temperature of a workpiece, but not affected by chemical composition of a workpiece. Thus, heat transfer coefficient measured in this section is applicable for other materials, e.g. JIS S45C.

\section{Determination of the Latent Heat for Martensitic Transformation}

\subsection{Experimental and Calculation Methods}

The latent heat values associated with martensitic trans-

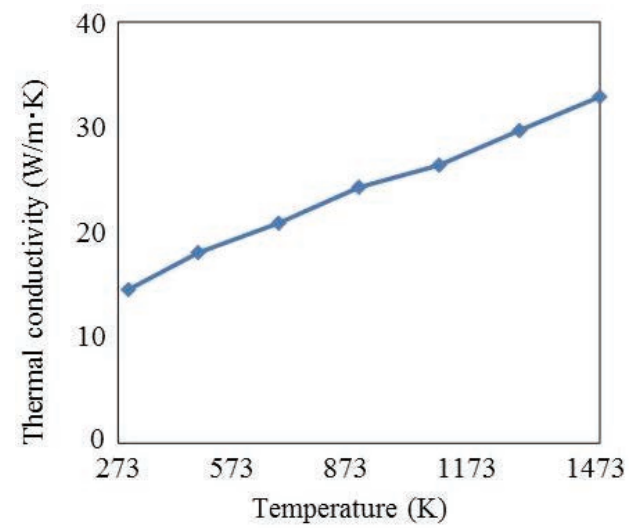

a. Thermal conductivity

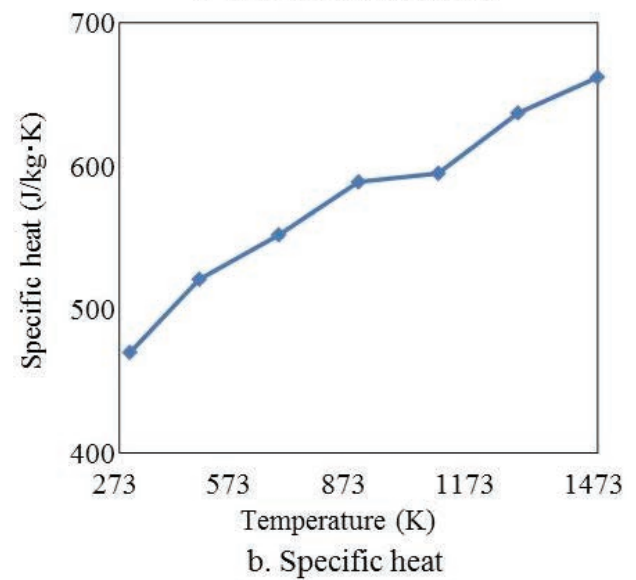

Fig. 7. The thermal properties of JIS SUS304 stainless steel. (Online version in color.)

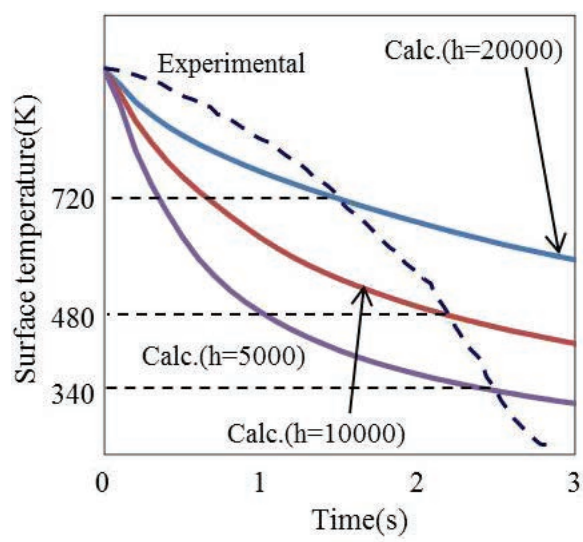

a. Transition of surface temperature (Experimental and calclations) formations were obtained via a combination of quenching experiments and simulations. These trials employed a thin walled ring-shaped workpiece and a ring-shaped cooling jacket, as shown in Fig. 14. During jet quenching, the temperature of the workpiece decreases on going from the surface to the interior, which creates a time lag in the martensitic transformation. Thus, if a columnar workpiece is used and the temperature is measured on its surface, the temperature will be affected by this sequential martensitic transformation. In order to correlate the measured temperatures with the latent heat of the transformation, a thin walled ring-shaped workpiece was employed. The workpiece was heated to $1273 \mathrm{~K}$ and maintained at that temperature for 20 $\mathrm{s}$ before being quenched by the jet. The material used for the workpiece was medium carbon steel (JIS S45C) and the workpiece surface temperature was measured using type $\mathrm{K}$ thermocouples welded on the front (point a in the figure) and back surface (point $b$ ).

Calculations that simulated quenching and phase transformation were also conducted to determine the latent heat values, taking into account the exothermic reaction associated with the martensitic transformation. The conditions used for these calculations are summarized in Table 1 . Case 1 used a constant heat transfer coefficient of $5000 \mathrm{~W} / \mathrm{m}^{2} \cdot \mathrm{K}$ to simulate heat transfer between the jet and the surface of the

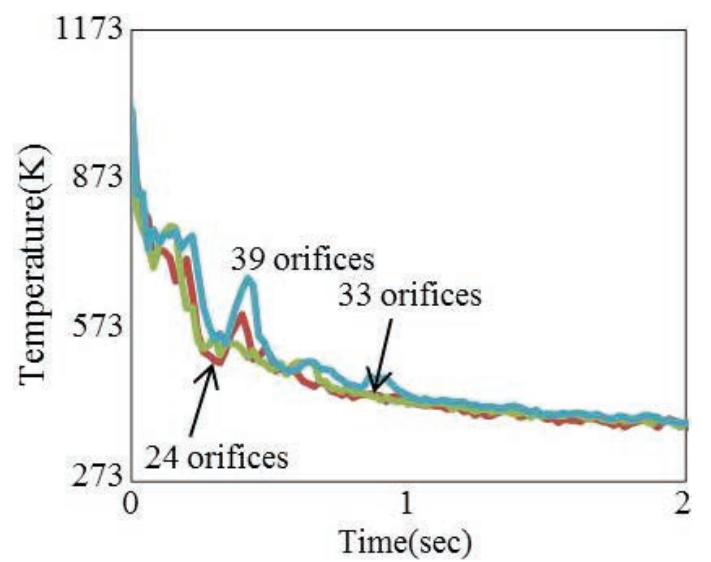

Fig. 9. The quenching curves obtained using various numbers of jet holes. (Online version in color.)

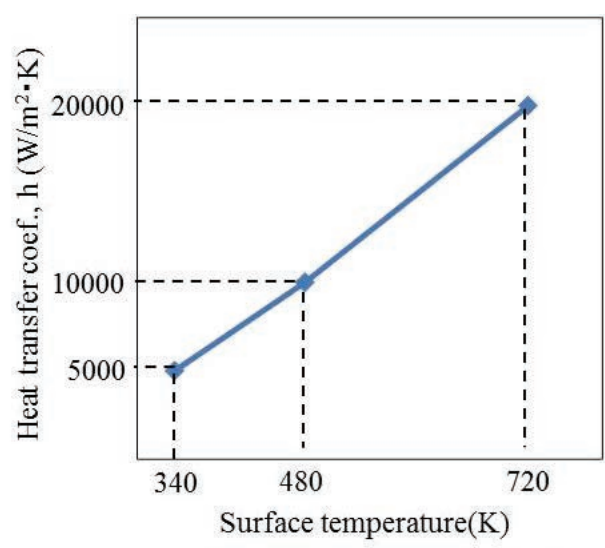

b. Identified heat transfer coefficient

Fig. 8. Schematic diagrams showing the process used to determine the temperature-dependent heat transfer coefficients. (Online version in color.) 


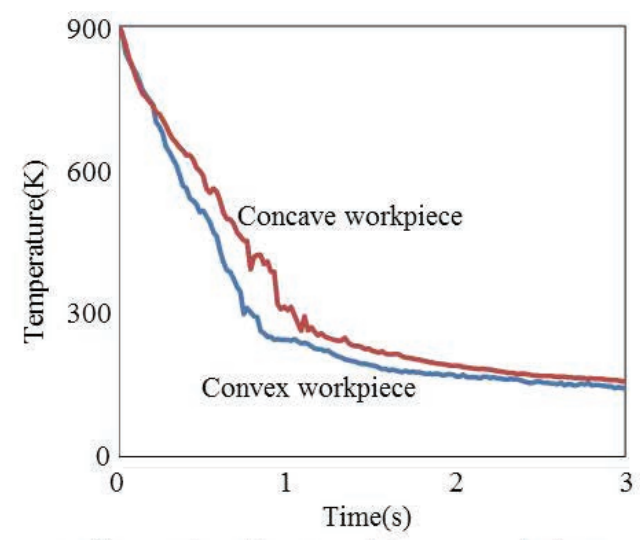

a. Comparison for quenching curves between convex and concave workpiece

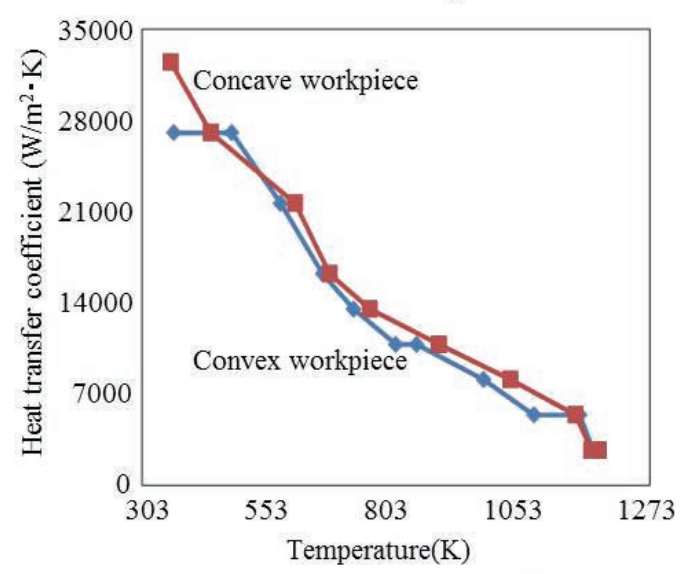

b. Comparison for heat transfer coefficients between convex and concave workpiece

Fig. 10. Experimental and calculation results. (Online version in color.)

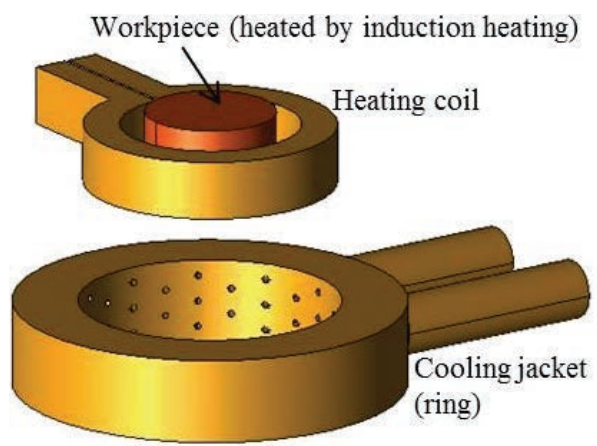

a. Heating

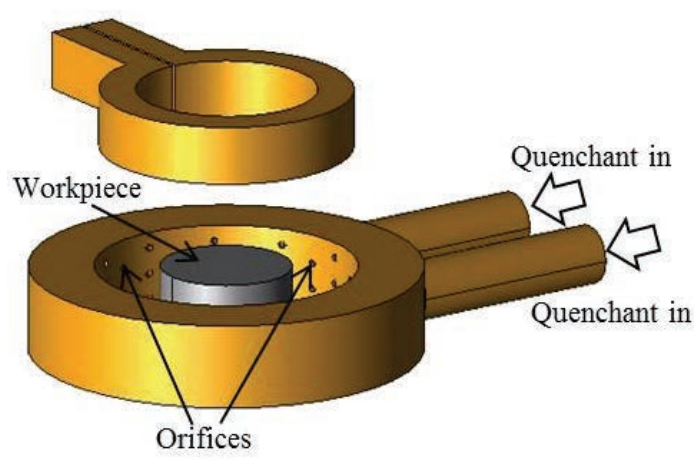

b. Quenching

Fig. 11. Schematic diagram of the apparatus used during the quenching experiment with a ring-shaped cooling jacket. (Online version in color.)
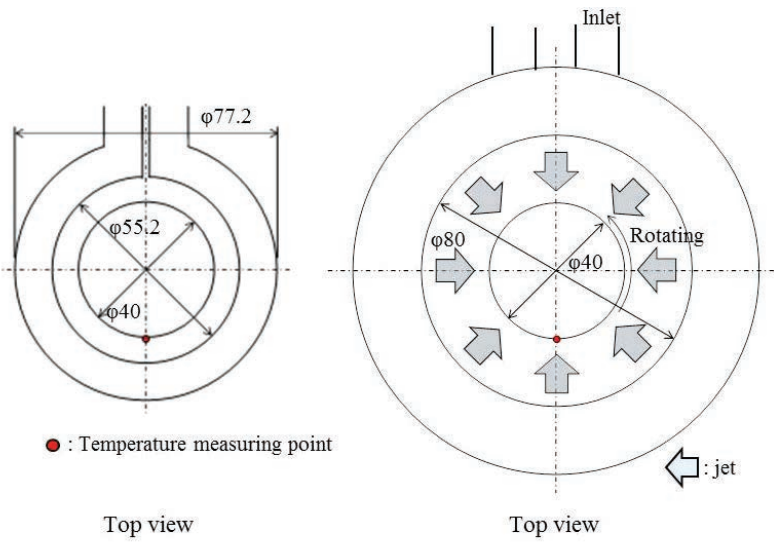

Top view

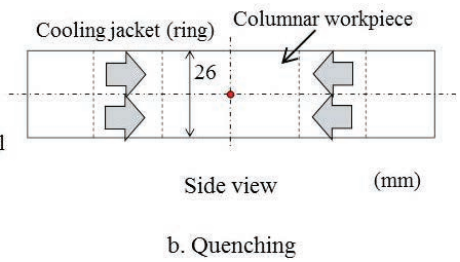

Fig. 12. The dimensions of the workpiece, heating coil and cooling jacket used to determine heat transfer coefficients. (Online version in color.)

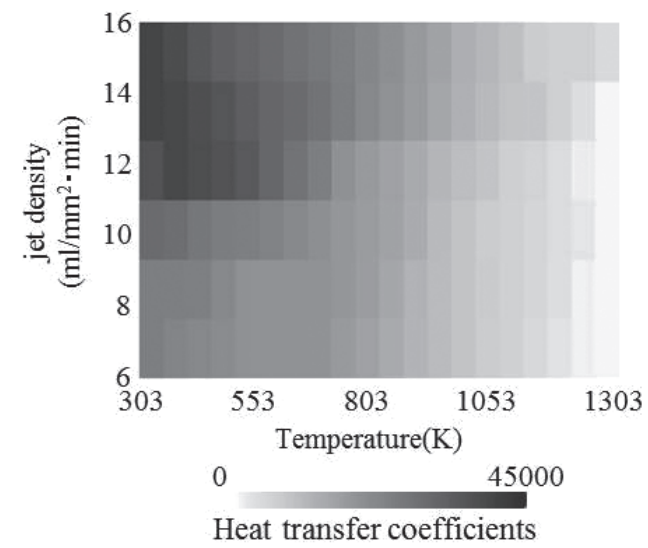

$\left(\mathrm{W} / \mathrm{m}^{2} \cdot \mathrm{K}\right)$

Fig. 13. The relationship between the jet density, workpiece surface temperature and heat transfer coefficient.

workpiece. In this case, the temperature-dependent thermal characteristics (thermal conductivity and specific heat, as in Fig. 15) for equilibrium transformations were considered. In case 2 , the temperature-dependent heat transfer coefficients which measured at 3-2 were determined. During quenching at a high cooling rate, supercooled austenite can appear, and so the thermal characteristics of supercooled austenite were calculated using the formulae: ${ }^{12}$

Thermal conductivity $=$

$20.76+0.009 \mathrm{~T}-3.2627(\mathrm{C} \%)-0.7598(\mathrm{Si} \%)-0.1432(\mathrm{Mn} \%)$

and

Specific heat $=0.0598 \mathrm{~T}+566$,

where $T$ is the temperature $(\mathrm{K})$. In cases 3 and 4 , the temperature-dependent heat transfer coefficients and thermal characteristics (Fig. 15) of supercooled austenite were all considered. In addition, an exothermic reaction corresponding to the latent heat for the martensitic transformation was also incorporated between $543 \mathrm{~K}$ (the onset temperature for 


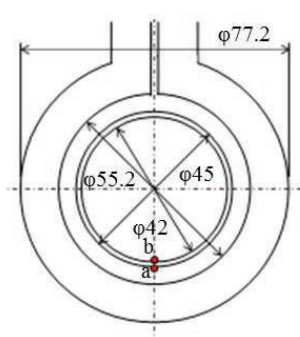

Top view

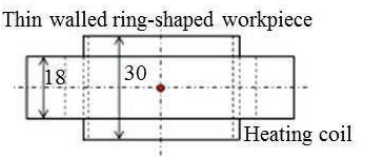

○ : Temperature measuring point Side view a. Heating

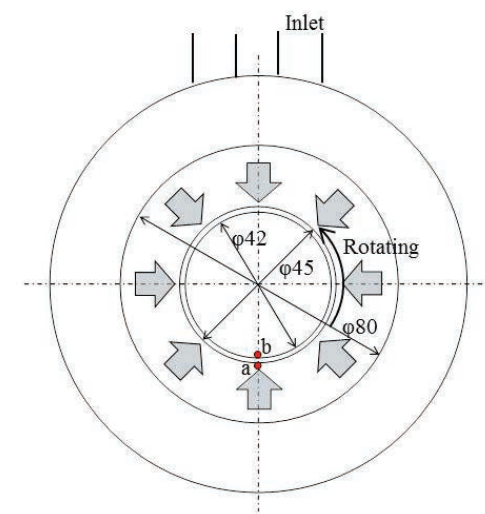

Top view
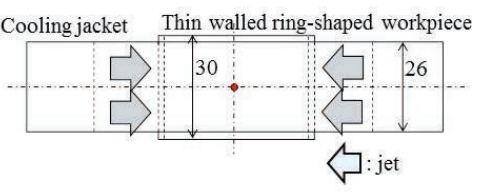

(mm)

Side view

b. Quenching
Cooling jacket Thin walled ring-shaped workpiece

Fig. 14. The dimensions of the workpiece, heating coil and cooling jacket used to determine latent heat values for martensitic transformations. (Online version in color.)

Table 1. The parameters employed during simulations.

\begin{tabular}{ccc}
\hline & Heat transfer coef. & $\begin{array}{c}\text { Latent heat for Martensitic } \\
\text { transformation }\end{array}$ \\
\hline Case1 & Constant $(5000 \mathrm{~W} / \mathrm{m} \cdot \mathrm{K})$ & Not considered \\
Case2 & Temperature dependent & Not considered \\
Case3 & Temperature dependent & Considered $(80 \mathrm{~kJ} / \mathrm{kg})$ \\
Case4 & Temperature dependent & Considered $(40 \mathrm{~kJ} / \mathrm{kg})$ \\
\hline
\end{tabular}

martensitic transformation, $\mathrm{M}_{\mathrm{s}}$ ) and $473 \mathrm{~K}$ (the end temperature for martensitic transformation, $\mathrm{M}_{\mathrm{f}}$ ). The enthalpy change for the martensitic transformation of $\mathrm{Cr}-\mathrm{Mo}$ steel (SAE $4140 \mathrm{H}$ ) has been reported to have a value of $640 \mathrm{MJ} /$ $\mathrm{m}^{3}{ }^{13)}$ and so this value (equivalent to $80 \mathrm{~kJ} / \mathrm{kg}$ ) was used as the initial value for the latent heat in case 3 . However, a value of $40 \mathrm{~kJ} / \mathrm{kg}$ was employed in case 4 because the amount of latent heat was different as a result of the higher cooling rate applied. The initial temperature of the workpiece was a uniform $1273 \mathrm{~K}$ and the mesh size was $1 \mathrm{~mm}$. The time step was $0.001 \mathrm{~s}$ prior to a reaction time of 0.5 $\mathrm{s}$, to accurately calculate the rapid temperature change and phase transformation during the initial stage of quenching, and $0.01 \mathrm{~s}$ from 0.5 to $3 \mathrm{~s}$. Calculations were conducted using the commercial FEM software package FORGE (TRANSVALOR Co., Ltd.).

\subsection{Latent Heat Results}

A comparison of the experimental and simulated results for the trials with the thin walled, ring-shaped workpieces is shown in Fig. 16. In case 1 (Fig. 16(a)), the calculated temperatures were higher than the experimental values throughout the entire quenching process. In addition, the accuracy of case 2 exceeded that of case 1 based on using the temperature-dependent heat transfer coefficients and supercooled austenite (Fig. 16(b)). However, the calcu-
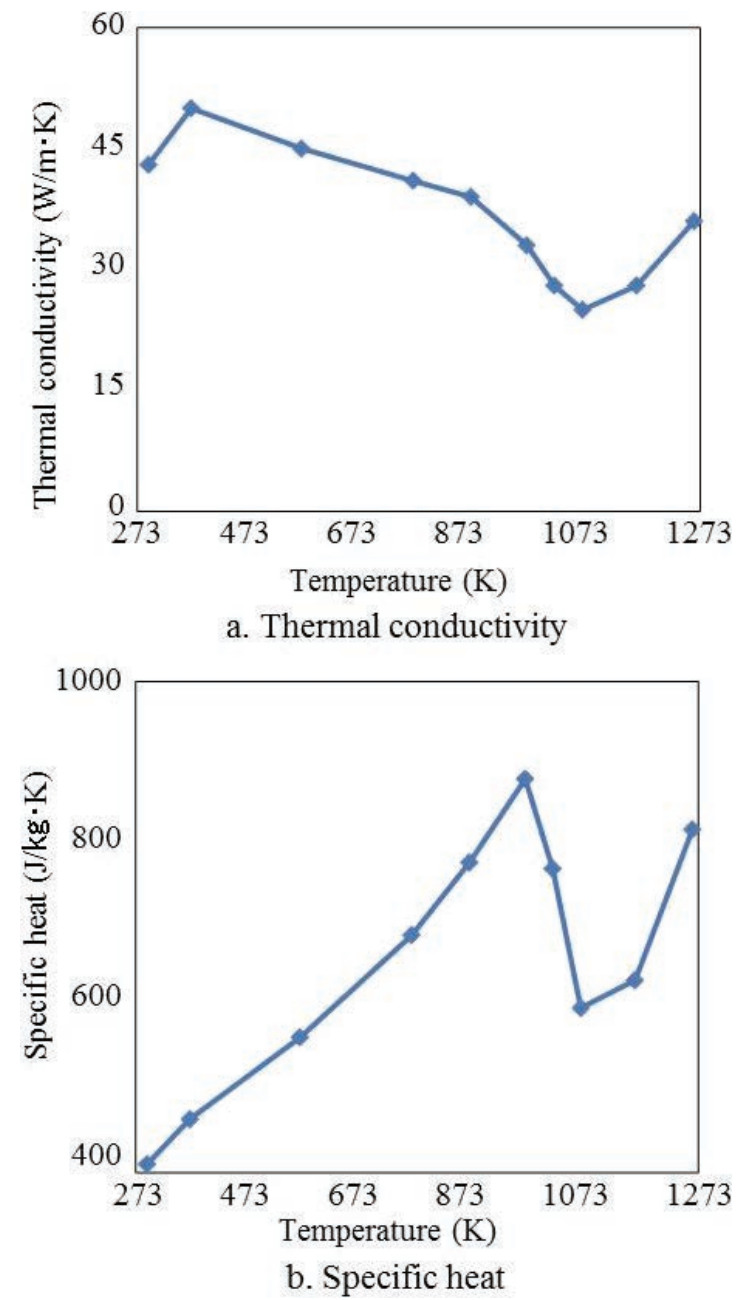

Fig. 15. The thermal properties of JIS S45C medium carbon steel. (Online version in color.)

lated temperatures were lower than the experimental data after $0.6 \mathrm{~s}$, especially at point b. In case 3 (Fig. 16(c)), the simulated temperatures were higher than the experimental temperatures after $0.6 \mathrm{~s}$. This result indicates that the latent heat value of $80 \mathrm{~kJ} / \mathrm{kg}$ that was used was much larger than the actual latent heat. In case 4 (Fig. 16(d)), the accuracy of the calculations after $0.6 \mathrm{~s}$ was improved compared to cases 2 and 3, while the calculated temperatures showed good agreement with the experimental data for the entire quenching process. The error between the experimental and calculated values at point $\mathrm{b}$ was less than $1 \mathrm{~K}$ at 0.9 s (Figs. 16(e) and 16(f)). These findings demonstrate that incorporating the latent heat for martensitic transformation is an effective means of improving the simulation accuracy at temperatures lower than $\mathrm{M}_{\mathrm{s}}$, and that $40 \mathrm{~kJ} / \mathrm{kg}$ is an appropriate value for the latent heat associated with the martensitic transformation during rapid cooling (Fig. 16(e)). In this calculation, latent heat due to phase transformation and magnetic transformation are not distinguished. Thus, latent heat of magnetic transformation is mixed in abovementioned latent heat value of $40 \mathrm{~kJ} / \mathrm{kg}$.

\section{Demonstration}

\subsection{Experimental and Calculation Methods}

The quenching of a gear was carried out to verify the 


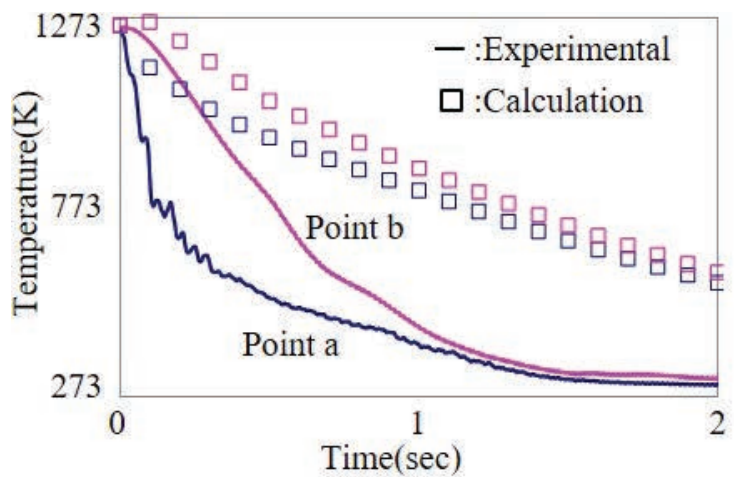

a. Case 1 (latent heat $=0 \mathrm{~kJ} / \mathrm{kg}$ )

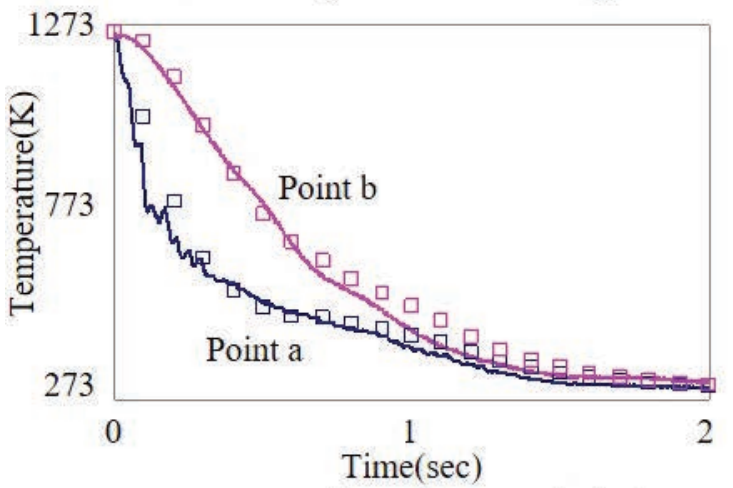

c. Case 3 (latent heat $=80 \mathrm{~kJ} / \mathrm{kg}$ )

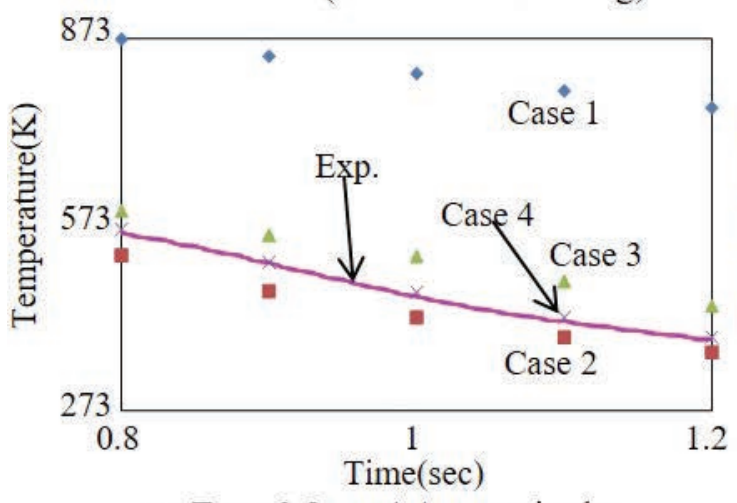

e. From $0.8 \mathrm{~s}$ to $1.1 \mathrm{~s}$ at point $\mathrm{b}$

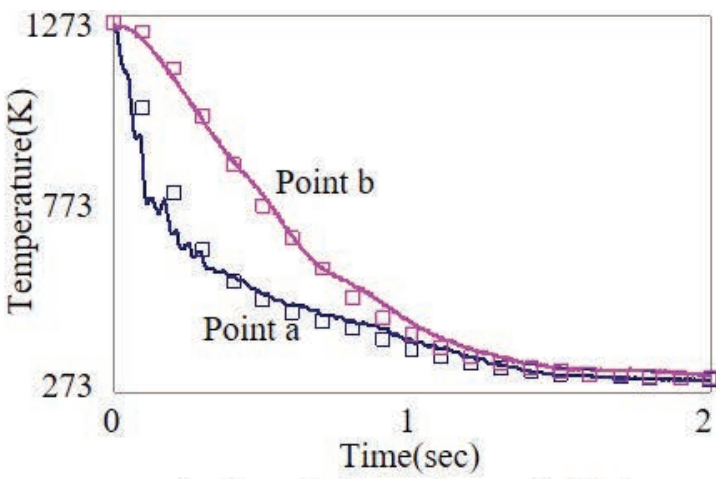

b. Case 2 (latent heat $=0 \mathrm{~kJ} / \mathrm{kg}$ )

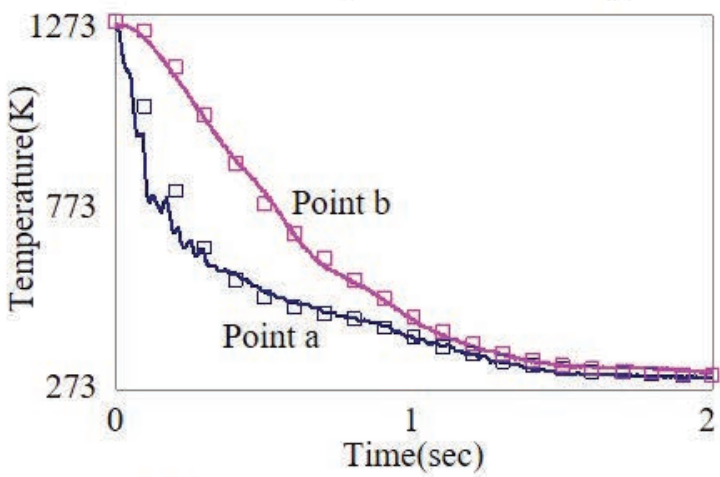

d. Case 4 (latent heat $=40 \mathrm{~kJ} / \mathrm{kg}$ )

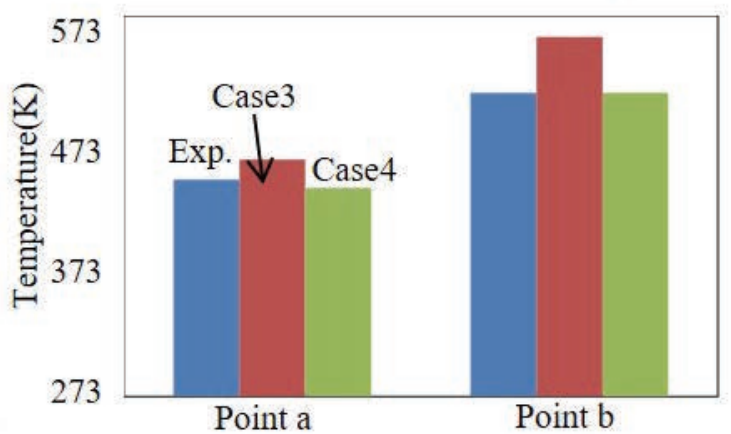

f. Temperatures of experimental, case 3 and case 4 at $0.9 \mathrm{~s}$

Fig. 16. A comparison of the experimental and calculated results for a cylindrical workpiece. (Online version in color.)

accuracy of the present simulation technique. The dimensions and positional relationships of the gear, the heating coil, and the cooling jacket used in these experiments are shown in Fig. 17. The gear was heated to $1323 \mathrm{~K}$ and maintained at that temperature for $20 \mathrm{~s}$, then quenched by a jet. The material used for the gear was medium carbon steel (JIS S45C) and the surface temperatures of the gear were monitored by type $\mathrm{K}$ thermocouples welded on the top (point a) and bottom surface (point b).

As demonstration, thermal and phase transformation calculations were conducted to simulate quenching of the gear and heat transfer coefficients for each surface area of the gear were obtained from the results (Fig. 13). The area segmentations employed during this process are defined in Fig. 18. In a thermal calculation, temperature at each mesh is calculated based on heat conduction in a workpiece and heat transfer between surface of a workpiece and coolant. In a phase transformation calculation, phase of each mesh is calculated based on its temperature which calculated at a just before thermal calculation and TTT diagram of S45C. If phase transformation occurs at this phase transformation calculation, exothermic reaction due to latent heat will be considered at a next thermal calculation. Thermal conductivity and specific heat shown in Fig. 15 were used for martensite, ferrite, pearlite and austenite. The formulae mentioned at section 4-1 was used to calculate thermal conductivity and specific heat of supercooled austenite. Density of a gear was a constant value of $7780 \mathrm{~kg} / \mathrm{m} 3$ at all temperatures. The martensitic transformation was considered to appear between $543 \mathrm{~K}(\mathrm{Ms})$ and $473 \mathrm{~K}(\mathrm{Mf})$, and $40 \mathrm{~kJ} / \mathrm{kg}$ was applied to amount of latent heat. For comparison purposes, calculations that did not consider the latent heat and distribution of the heat transfer coefficients were also conducted using a constant heat transfer coefficient of $20000 \mathrm{~W} / \mathrm{m}^{2} \cdot \mathrm{K}$ for all areas. The mesh size was $1 \mathrm{~mm}$ and the time step during calculations was set to $0.01 \mathrm{~s}$ in both calclations. Calculations were conducted using the commercial FEM software package FORGE (TRANSVALOR Co., Ltd.). 


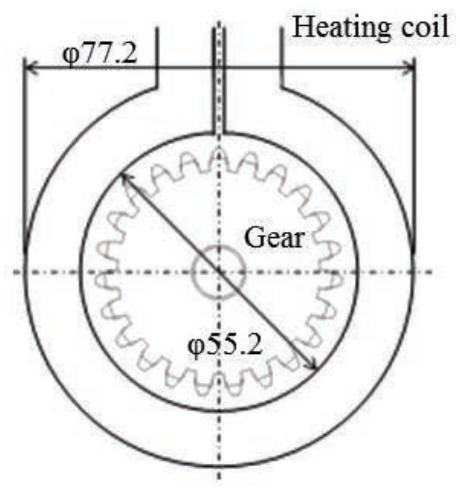

Top view

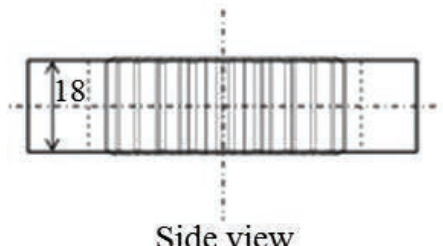

Side view

a. Heating

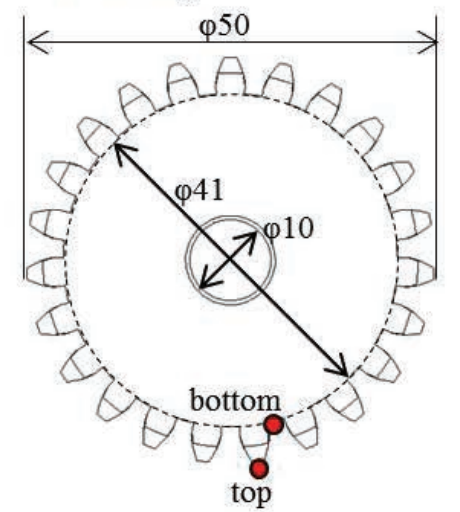

Top view

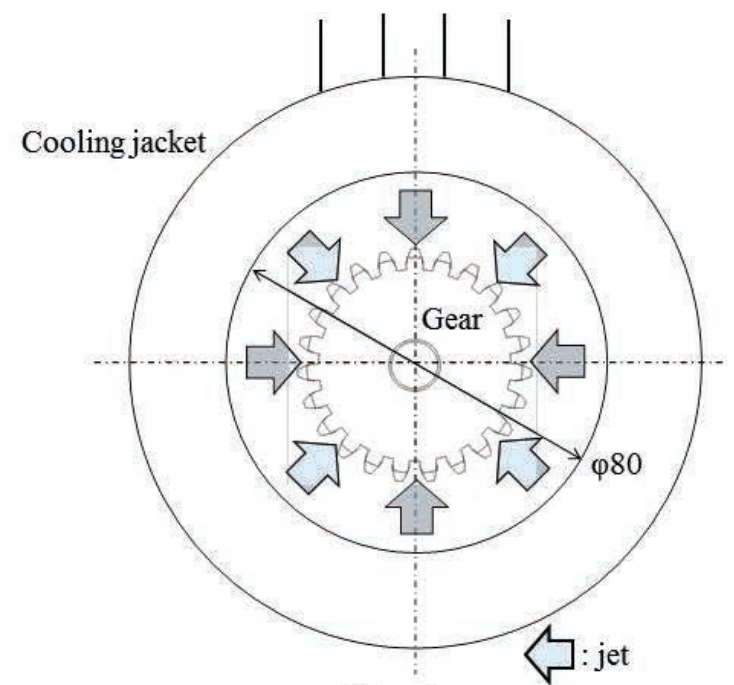

Top view

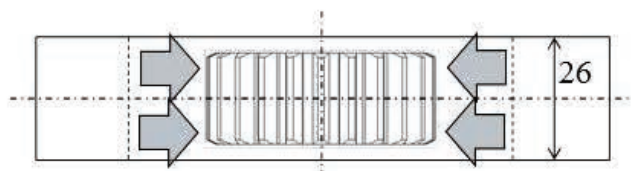

Side view

b. Quenching

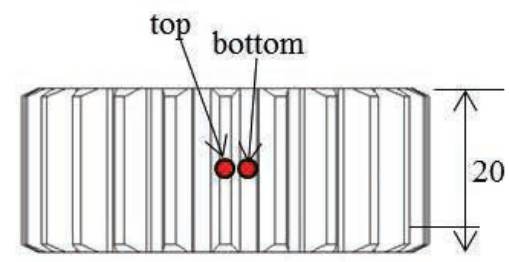

$\mathbf{0}$ : Temperature measuring points

$(\mathrm{mm})$

c. Dimensions and temperature measurement points of a gear

Fig. 17. The dimensions of the gear, heating coil and cooling jacket used for quenching experiments. (Online version in color.)

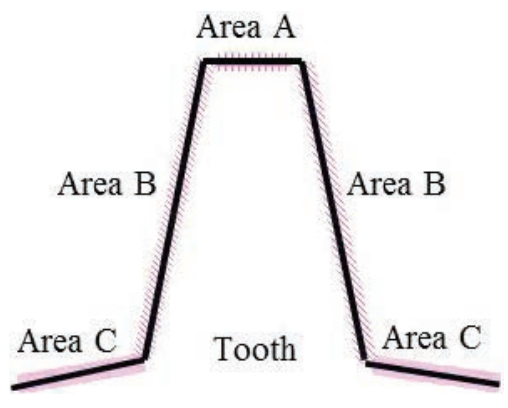

Fig. 18. The area segments used to obtain heat transfer coefficients (including a view of a gear tooth). (Online version in color.)

\subsection{Experimental and Calculated Results}

A comparison between the experimental and simulated results is shown in Fig. 19, from which it is evident that

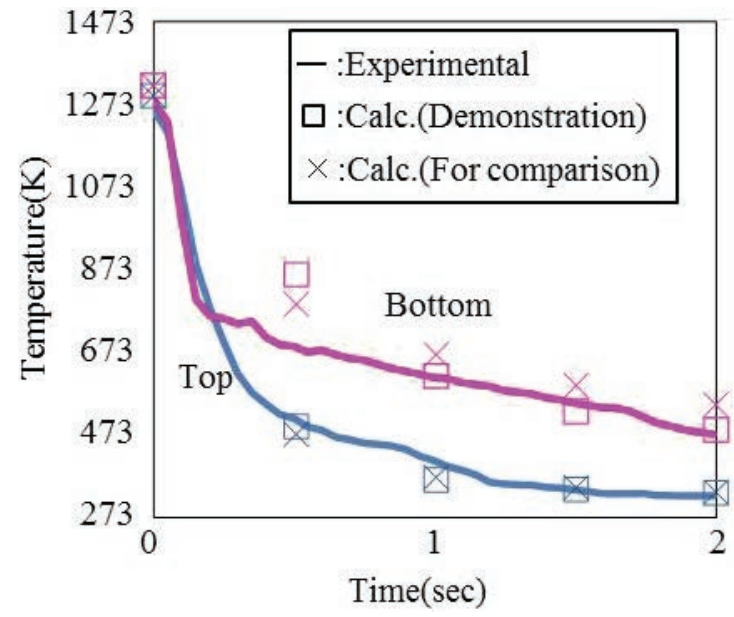

Fig. 19. A comparison of the experimental and calculated results for the gear. (Online version in color.) 
the calculated temperatures exhibited good agreement with the experimental data at the top of the gear during the entire quenching process. The discrepancy between calculated and experiment values was larger at the base but this error was reduced when considering the latent heat and distribution of heat transfer coefficients after $1 \mathrm{~s}$. These results indicate that taking into account the heat transfer coefficients determined from the jet density and the latent heat for the martensitic transformation in conjunction with rapid cooling is applicable to quenching simulations of parts having complicated shapes.

\section{Conclusions}

Jet quenching simulations were conducted, taking into account heat transfer coefficients that depend on the surface temperature of the workpiece and the jet density, as well as the appearance of supercooled austenite and the latent heat for martensitic transformation under rapid cooling. These simulations were conducted without CFD calculations. Consideration of supercooled austenite improved the accuracy of such modeling above $473 \mathrm{~K}$, and the incorporation of the latent heat associated with martensitic transformation under rapid cooling improved the accuracy below 473 K. Heat transfer coefficients determined based on the jet density were found to be useful during simulation of the quenching of complex parts. Both the quenching conditions and the shape of the cooled surface can evidently be summarized in the jet density. This simulation method could potentially be applied to the design of the cooling jacket, the positional relationship between the cooling jacket and workpiece, and to the optimization of cooling parameters such as the jet flow rate and cooling time, without requiring a trial-and-error approach.

\section{REFERENCES}

1) K. Fujimura, Y. Oohashi and Y. Onoda: Denki Seiko (Electr. Furn. Steel), 68 (1997), 129 (in Japanese).

2) A. Borgenstam, L. Höglund, J. Ågren and A. Engström: J. Phase Equilib., 21 (2000), 269.

3) B. L. Ferguson, Z. Li and A. M. Freborg: Comput. Mater. Sci., 34 (2005), 274.

4) H. Takeuchi and Y. Yogo: ISIJ Int., 59 (2019), 551

5) S. Fukuda: Tetsu-to-Hagané, 74 (1988), 1535 (in Japanese).

6) D. Greif, R. Kopun, N. Kosir and D. Zhang: Int. J. Automot. Eng., 8 (2017), 45 .

7) T. Horino, F. Ikuta, Y. Misaka, K. Kawasaki and Y. Tomota: Netsu Shori (J. Jpn. Soc. Heat Treat.), 55 (2015), 106 (in Japanese).

8) G. C. Lin, X. M. Xiong, J. X. Zhang and Q. Wei: J. Therm. Anal. Calorim., 81 (2005), 41.

9) J. L. Lee, J. K. Chen, Y. T. Pan and K. C. Hsieh: ISIJ Int., 39 (1999), 281.

10) Z. Q. Kuang, J. X. Zhang, X. H. Zhang, K. F. Liang and P. C. W. Fung: Scr. Mater., 42 (2000), 795.

11) N. Nakata, T. Kuroki, A. Fujibayashi and Y. Utaka: Tetsu-to-Hagané, 99 (2013), 635 (in Japanese).

12) J. Miettinen: Metall. Mater. Trans. B, 28 (1997), 281.

13) E. P. Silva, P. M. C. L. Pacheco and M. A. Savi: Proc. 17th Int. Congr. Mechanical Engineering (COBEM 2003), ABCM, Rio de Janeiro, (2003), 307. 